\title{
Role of the left aortic arch and blood flows in embryonic American alligator (Alligator mississippiensis)
}

\author{
John Eme $\cdot$ Dane A. Crossley II $\cdot$ James W. Hicks
}

Received: 23 December 2009/Revised: 21 May 2010/ Accepted: 20 June 2010/Published online: 30 October 2010

(C) The Author(s) 2010. This article is published with open access at Springerlink.com

\begin{abstract}
All embryonic and fetal amniotes possess a ductus(i) arteriosus(i) that allows blood to bypass the pulmonary circulation and the non-functional lungs. The central hemodynamic of embryonic reptiles are unique, given the additional systemic aorta that allows pulmonary circulatory bypass, the left aorta (LAo). The LAo exits in the right ventricle or 'pulmonary side' of reptilian hearts in both embryos and adults, but its functional significance in ovo is unknown. This study investigated the role of the LAo in embryonic American alligators by surgically occluding the LAo and measuring oxygen consumption and, in addition, measured hemodynamic responses to hypoxia in embryonic alligators. We measured systemic cardiac output and primary chorioallantoic membrane (CAM) artery blood flow for normoxic and hypoxic-incubated $\left(\begin{array}{llll}10 \% & \mathrm{O}_{2}\end{array}\right)$ American alligator embryos (Alligator mississippiensis). Chronic blood flow (1-124 h) in the primary CAM artery for hypoxic-incubated embryos $\left(92 \pm 26 \mathrm{ml} \mathrm{min}^{-1} \mathrm{~kg}^{-1}\right)$ was elevated when compared with normoxic-incubated embryos $\left(29 \pm 14 \mathrm{ml} \mathrm{min}^{-1}\right.$ $\left.\mathrm{kg}^{-1}, N=6 ; P=0.039\right)$. For hypoxic-incubated embryos,
\end{abstract}

Communicated by H.V. Carey.

Electronic supplementary material The online version of this article (doi:10.1007/s00360-010-0494-6) contains supplementary material, which is available to authorized users.

J. Eme $(\square) \cdot$ D. A. Crossley II

Department of Biological Science,

University of North Texas, 1155 Union Circle,

PO Box 305220, Denton, TX 76203-5017, USA

e-mail: johneme34@gmail.com

URL: http://web.mac.com/jeme/Site/Home.html

J. W. Hicks

Ecology and Evolutionary Biology, University of California,

Irvine, 321 Steinhaus Hall, Irvine, CA 92697-2525, USA acute LAo blood flow $\left(49.6 \pm 24.4 \mathrm{ml} \mathrm{min}^{-1} \mathrm{~kg}^{-1}\right)$ was equivalent to the combined flow of the three systemic great vessels that arise from the left ventricle, the right aorta, common carotid and subclavian arteries $(43.6 \pm 21.5 \mathrm{ml}$ $\min ^{-1} \mathrm{~kg}^{-1}, N=5$ ). Similarly, for normoxic-incubated embryos, LAo blood flow $\left(27.3 \pm 6.6 \mathrm{ml} \mathrm{min}^{-1} \mathrm{~kg}^{-1}\right)$ did not statistically differ from the other three vessels (18.4 $\pm 4.9 \mathrm{ml} \mathrm{min}^{-1} \mathrm{~kg}^{-1}, N=5$ ). This study contains the first direct test of LAo function and the first measurements of blood flow in an embryonic reptile. These data support the hypotheses that embryonic alligators utilize the LAo to divert a significant amount of right ventricular blood into the systemic circulation, and that CAM blood flow increases following chronic hypoxic conditions. However, surgical occlusion of the LAo did not affect egg $\dot{V}_{\mathrm{O}_{2}}$, supporting the hypothesis that the LAo of reptiles is not critical to maintain in ovo oxygen consumption.

Keywords Cardiac shunt - Chorioallantoic membrane . Ductus arteriosus - Hypoxia $\cdot$ Left aorta $\cdot$ Reptile
Abbreviations
CAM Chorioallantoic membrane
CCA Common carotid artery
fH Heart rate
LAo Left aorta/left aortic arch
LV Left ventricle
$\dot{Q}_{\mathrm{CCA}} \quad$ Blood flow in the CCA
$\dot{Q}_{\text {LAo }} \quad$ Blood flow in the LAo
$\dot{Q}_{\mathrm{LV}} \quad$ Cardiac output of the left ventricle, i.e., sum of $\dot{Q}_{\mathrm{RAo}}, \dot{Q}_{\mathrm{CCA}}$ and $\dot{Q}_{\mathrm{SCA}}$ blood flows
$\dot{Q}_{\text {RAo }} \quad$ Blood flow in the RAo
$\dot{Q}_{\text {SCA }} \quad$ Blood flow in the SCA 
RAo Right aorta

SCA Subclavian artery

$\dot{V}_{\mathrm{O}_{2}} \quad$ Oxygen consumption rate $\left(\mathrm{ml} \mathrm{O}_{2} \mathrm{~h}^{-1}\right)$

\section{Introduction}

A four-chambered heart consisting of two distinct atria and ventricles is present in crocodilians, birds and mammals, but retention of the ancestral dual aortic arch system in adults is found only in crocodilians (Hicks 1998). The left aortic arch (LAo) in adult crocodilians results in the capacity for a rightto-left cardiac shunt (R-L shunt), in which a fraction of systemic venous blood re-enters the systemic circulation (sometimes called a "pulmonary-bypass shunt"). This unique circulatory arrangement has been hypothesized to be of adaptive significance for crocodilians in a number of ecological and physiological scenarios, such as extending aerobic dive times (Grigg and Johansen 1987) and facilitating digestion by carrying $\mathrm{CO}_{2}$ to the stomach to aid gastric acid secretion (Jones and Shelton 1993; Farmer et al. 2008). However, these hypothesized physiological functions of $\mathrm{R}-\mathrm{L}$ cardiac shunt may not be experimentally supported in crocodilians and other reptiles (Hicks and Wang 1996). For example, recent studies have demonstrated that surgical reduction or elimination of R-L cardiac shunt did not alter $\dot{V}_{\mathrm{O}_{2}}$ in a freely diving turtle (Trachemys scripta; Wang and Hicks 2008) or American alligator (Alligator mississippiensis; Eme et al. 2009). In addition, chronic surgical removal of $\mathrm{R}-\mathrm{L}$ cardiac shunt did not markedly alter growth in agematched juvenile alligators (Eme et al. 2010).

An alternative hypothesis is that the LAo and $\mathrm{R}-\mathrm{L}$ cardiac shunt have no adaptive significance in juvenile or adult reptiles, but are critically important during embryonic development (Hicks 2002). All embryonic and fetal amniotes possess cardiac morphologies that allow mixing of oxygenated and deoxygenated blood. In fetal mammals and embryonic birds, a R-L cardiac shunt via ductus(i) arteriosus(i) is responsible for directing the majority of systemic venous return away from the non-functional lungs and into the systemic circulation via a single aorta exiting the left ventricle. In embryonic crocodilians, two vascular routes can direct right ventricular blood away from the non-functional lungs, the ducti arteriosi and the LAo (Ferguson 1985). The right and left embryonic crocodilian ventricles receive oxygenated blood originating from CAM venous return, similar to birds. The crocodilian LAo emerges from the right ventricle alongside the pulmonary artery, and the right aortic arch emerges from the left ventricle (Webb 1979). A key membrane is the chorioallantoic membrane (CAM), which serves as the gas exchange structure for the developing crocodilian (as well as for reptiles and birds). The CAM arteries arise from the iliac arteries, which in turn arise from the abdominal aorta. In ovo, crocodilians' right and left aortic arches are connected via the foramen of Panizza (FoP) (Panizza 1833) immediately downstream of their aortic valves, and the FoP is present relatively late in development, $\sim 65 \%$ (Seymour et al. 2004). In addition, throughout in ovo development, these major vessels fuse much further downstream to become the abdominal aorta, similar to the arrangement of other non-crocodilian reptilian adults, and unlike the right aorta-anatomosis-left aorta connection in crocodilian adults (personal observations, and see Supplementary material Figs. 1, 2 for a digital subtraction angiography video of blood flow and image of embryonic alligator abdominal aortic fusion, respectively). Just prior to this fusion, a major arterial branch, the celiac, branches off the LAo supplying arterial blood to the stomach and the small intestine. A branch of the celiac artery divides toward the left and right portions of the embryonic stomach, while a third branch continues posterior toward the upper small intestine. The hemodynamics of blood flows between crocodilians' two arches' communication points, the FoP and abdominal aortic fusion, are not known in ovo. However, a portion of blood from the LAo could possibly continue to feed the large vessel comprises the fused right and left aorta, the abdominal aorta, which supplies the CAM, as well as feeding the rudimentary gut via the celiac (Supplementary Figs. 1, 2). If the LAo is important to maintain adequate perfusion and normal blood flows during development, obstruction or occlusion of the LAo could cause a decrement in embryonic oxygen consumption.

In embryonic chickens, blood flow in the CAM artery has been quantified in response to changes in environmental oxygen (e.g., Tazawa and Mochizuki 1977; Piiper et al. 1980; Tazawa et al. 1985; van Golde et al. 1997; Mulder et al. 1998; Mulder et al. 2002; Seymour and Wagner-Amos 2008). These studies demonstrate that vascular perfusion can vary in response to external stressors in avian embryos. While natural variation in nest $P_{\mathrm{O}_{2}}$ may be limited in an avian nest, American alligator and other crocodilians lay eggs in mound nests, which may subject the embryos to both acute and chronic hypoxia (Lutz and Dunbar-Cooper 1984; Seymour et al. 1986; Booth 1998; Booth 2000). Under these conditions, blood flow distribution in crocodilian embryos may be altered as either a passive or actively regulated response to differences in nest $P_{\mathrm{O}_{2}}$ microclimate. However, an assessment of blood flow in embryonic crocodilians has yet to be completed.

In this study, we investigated the physiological role of the LAo in normoxic-incubated American alligator 
embryos by surgically occluding this vessel and measuring egg oxygen consumption $\left(\dot{V}_{\mathrm{O}_{2}}\right)$. In addition, we measured systemic cardiac output and CAM blood flow in normoxicand hypoxic-incubated embryonic alligators. We tested the hypotheses that surgical occlusion of the LAo would decrease egg oxygen consumption, and that chronic hypoxic-incubation would increase systemic cardiac output and CAM blood flow in alligator embryos. If the LAo supports a large amount of forward flow in embryonic alligators, this would support the hypothesis that the LAo has an important function(s) during ontogeny. In addition, if ablation of the LAo decreases egg $\dot{V}_{\mathrm{O}_{2}}$, it would indicate that this blood vessel is essential for maintaining normal embryonic oxygen consumption.

\section{Methods}

Alligator embryo acquisition and incubation

American alligator eggs (Alligator mississippiensis) were obtained from the Rockefeller Wildlife Refuge in Grand Chenier, LA, USA and transported by automobile to the University of North Dakota in Grand Forks, ND, USA. Eggs from each clutch were staged by a single investigator (JE) to determine each clutches' time post-laying as previously described (Ferguson 1985; Crossley et al. 2003; 72 days total incubation period at $30^{\circ} \mathrm{C}$ ). Embryos were incubated at $30^{\circ} \mathrm{C}$ in either a walk-in, constant temperature room or in an incubator, ensuring that all embryos were developing as females (Advanced Intellus environmental incubator; Percival Scientific Inc. Perry, IA, USA). All embryos were incubated in plastic containers containing a $2: 1$, vermiculite:water mixture. Water content of the vermiculite, determined by mass at the beginning of incubation, was maintained by weighing the box twice weekly, with water added as needed.

Embryos used in the experiment on chronic CAM blood flow $(N=12)$ and embryos used in the experiment on acute cardiac output $(N=10)$ were divided into two experimental groups, hypoxic-incubation $\left(10 \% \mathrm{O}_{2}\right.$; $N=11)$ and normoxic-incubation $\left(21 \% \quad \mathrm{O}_{2} ; N=11\right)$. Hypoxic or normoxic incubation began at $\sim 20 \%$ of development, and $10 \% \mathrm{O}_{2}$ slightly exceeds previously published minimum values of $\sim 85$ torr for the American crocodile (Crocodylus acutus) (Lutz and Dunbar-Cooper 1984). Containers were placed inside large Ziplock ${ }^{\circledR}$ bags and sealed, and two holes in the bags allowed parallel inflow and outflow of gas. Oxygen mixtures were set using a Sechrist Air-Oxygen mixer (Model 3500HL; Sechrist Industries, Inc. Anaheim, CA, USA), downstream of compressed $\mathrm{N}_{2}$ and air or air alone, with mixtures passing through a $\mathrm{H}_{2} \mathrm{O}$-bubbler to ensure adequate water saturation of $\geq 80-90 \%$ relative humidity. Gas composition was monitored with an oxygen analyzer (S-3AII, Ametek Applied Electrochemistry, IL, USA) connected to a PowerLab ${ }^{\circledR}$ data recording system (ADInstruments, CO, USA) connected to a Macintosh computer (Apple, Inc. Cupertino, CA, USA) running Chart $^{\circledR}$ software ( $v$ 5.4.2 ADInstruments), and data recorded at $100 \mathrm{~Hz}$.

Chronic blood flow in the primary CAM artery for normoxic- and hypoxic-incubated embryos

At $80 \%$ of development, between 56 and 58 days postlaying, eggs were removed from their incubators and candled to determine orientation of the embryo $(N=12,6$ from $10 \% \mathrm{O}_{2}$ and 6 from $21 \% \mathrm{O}_{2}$ ). This developmental timepoint was selected because embryos were predicted to be large enough to instrument the primary CAM artery, but not so large as to obstruct surgical access to the vessel. Eggs were placed in a sterilized, temperature-controlled surgical chamber at $30^{\circ} \mathrm{C}$ under normoxic conditions, and a portion of the eggshell removed under a dissection microscope (Leica MZ6; Leica Microsystems, Waukegan, IL, USA). The primary CAM artery was isolated for flow probe instrumentation. A crystal Doppler Transonic ${ }^{\circledR}$ flow probe was placed around the vessel and fixed to the shell with cyanoacrylic glue $(0.7$ or $1.0 \mathrm{~mm}$; Transonic Inc., Ithaca, NY, USA). A portion of a rubber glove was carefully glued around the open part of the shell, making sure the seal was air-tight to prevent desiccation, and the egg returned to its appropriate oxic incubation. Flow in the primary CAM artery for each embryo was monitored daily, on an intermittent basis until signal was lost, between 1 and $24 \mathrm{~h}$ each day per embryo. Flow was monitored using a Transonic T206 connected to a PowerLab ${ }^{\circledR}$ data recording system connected to a Macintosh computer running Chart ${ }^{\circledR}$ software, and data recorded at $100 \mathrm{~Hz}$. Heart rate $(f H)$ was determined with a software tachograph. Embryos were not exposed to any form of anesthesia. When flow signal was lost, the embryo was euthanized with an overdose of isoflurane, and embryonic wet mass and wet heart mass, atria and ventricles, were determined $\pm 0.001 \mathrm{~g}$ using an analytical balance (Mettler Toledo XS204; Columbus, OH, USA).

Acute cardiac output for normoxic and hypoxicincubated embryos

At $90 \%$ of development, between 63 and 66 days postlaying, eggs were removed from their incubators and candled to determine orientation of the embryo and location of an accessible tertiary CAM artery $(N=10,5$ from $10 \% \mathrm{O}_{2}$ and 5 from $21 \% \mathrm{O}_{2}$ ). This developmental 
timepoint was selected because embryos were predicted to be large enough for instrumentation of the great blood vessels. Eggs were placed in a temperature-controlled surgical chamber at $30^{\circ} \mathrm{C}$ under normoxic conditions, and a portion of the eggshell removed under the dissection microscope. Embryos were then anesthetized (confirmed as non-responsiveness to mechanical stimulation) with isoflurane (Isoflo; Abbott laboratories, North Chicago, IL, USA). The embryo's ventral surface was exposed, and a $2-\mathrm{cm}$ midline incision made through the scales. Skin was blunt dissected away from the underlying musculature, and the pericardium and great vessels exposed by cutting through the musculature and the sternum. The pericardium was opened to expose the ventricles and great vessels. During the surgical preparation and experimentation, the embryo's head was contained within the amniotic fluid.

Blood flow in the right aorta $\left(\dot{Q}_{\text {RAo }}\right)$, subclavian artery $\left(\dot{Q}_{\mathrm{SCA}}\right)$, common carotid artery $\left(\dot{Q}_{\mathrm{CCA}}\right)$ and left aorta $\left(\dot{Q}_{\text {LAo }}\right)$ were determined using crystal doppler Transonic ${ }^{\circledR}$ flow probes $(0.7,1.0$ or $2.0 \mathrm{~mm})$ under sequential normoxic and hypoxic conditions. Gas composition was monitored with an oxygen analyzer ( $\mathrm{S}-3 \mathrm{AI})$ and altered using a Sechrist Air-Oxygen mixer (3500HL) downstream of compressed $\mathrm{N}_{2}$ and air. $\dot{Q}_{\mathrm{LAo}}$ was determined with a single flow probe $(0.7$ or $1.0 \mathrm{~mm})$, and $\dot{Q}_{\mathrm{RAo}}, \dot{Q}_{\mathrm{SCA}}$ and $\dot{Q}_{\mathrm{CCA}}$ were determined with one or two flow probes, either all three vessels simultaneously within a $2.0 \mathrm{~mm}$ probe or the RAo and SCA simultaneously in a $1.0 \mathrm{~mm}$ probe and the CCA separately in a 0.7 or $1.0 \mathrm{~mm}$ probe. After 10-min of stable flows, normoxic-incubated embryos were exposed to acute hypoxia $\left(14.3 \pm 1.6 \% \mathrm{O}_{2}\right.$; mean $\left.\pm \mathrm{SEM}\right)$ for $10 \mathrm{~min}$, and blood flows were monitored during hypoxic exposure and for 5-10 min following a return to normoxia. For hypoxic-incubated embryos, stable blood flows were monitored for at least $10 \mathrm{~min}$ in normoxia, and subsequently embryos were exposed to hypoxia $\left(14.4 \pm 1.4 \% \quad \mathrm{O}_{2}\right)$ for the remainder of the experiment, 10-20 min. Blood flow was monitored using a Transonic T206 or T106, and blood flow monitored using a PowerLab ${ }^{\circledR}$ data recording system connected to a Macintosh computer running Chart ${ }^{\circledR}$ software, and data recorded at $100 \mathrm{~Hz}$. $f H$ was determined with a software tachograph. Following completion of each trial, the embryo was euthanized with an overdose of isoflurane, and embryonic wet mass and wet heart mass, atria and ventricles, were determined $\pm 0.001 \mathrm{~g}$ using the analytical balance.

Occlusion of the left aorta (LAo) and $\dot{V}_{\mathrm{O}_{2}}$ in alligator embryos

At $95 \%$ of development, between 67 and 69 days postlaying, normoxic-incubated eggs were removed from their incubators and candled to determine orientation of the embryo $(N=8,4$ sham-operated and 4 experimental, LAo-occluded). This developmental timepoint was selected because it represents the point of maximal metabolic rate prior to lung ventilation. Eggs were placed in a temperature-controlled surgical chamber at $30^{\circ} \mathrm{C}$ under normoxic conditions, and a portion of the eggshell removed under the dissection microscope. Embryos were then anesthetized (confirmed as non-responsiveness to mechanical stimulation) with sodium pentobarbital (50 mg kg${ }^{-1}$; Abbott Laboratories, North Chicago, IL, USA). The embryo's ventral surface was exposed, and a 2$\mathrm{cm}$ midline incision made through the scales. Skin was blunt dissected away from the underlying musculature, and the pericardium and great vessels were exposed by cutting through the musculature and the sternum. The pericardium was not opened. During the surgical preparation and experimentation, the embryo's head was contained within the amniotic fluid. For LAo-occluded embryos, the LAo was isolated downstream of the great vessel truncus and occluded with 4-0 sterile silk suture (Ethicon, Somerville, NJ, USA). For the sham group, the surgical procedure was identical to the LAo-occluded group, but the LAo was not isolated and no suture wrapped around it. The musculature and skin were seen shut in succession with 3-0 silk suture (Ethicon). A portion of a rubber glove was carefully glued around the open part of the shell, making sure the seal was air-tight to prevent desiccation. Although it has been demonstrated that occlusion of the LAo upstream of the FoP is necessary to completely eliminate the capacity for systemic blood to re-enter the systemic circulation from the right ventricle in alligators (Farmer et al. 2008; Eme et al. 2009; Eme et al. 2010), this delicate surgical procedure was not reliably repeatable in ovo, and its success was not verifiable (e.g., using $\mathrm{H}_{2}$-electrode technique in Eme et al. 2009). Therefore, we only occluded the LAo well downstream of the Foramen, just downstream of the great vessel truncus.

Immediately following surgery, eggs were returned to the $30^{\circ} \mathrm{C}$ walk-in, constant temperature room for experimentation. As the embryo recovered from surgery ( 2-3 h post operation) and two additional days following surgery, $\dot{V}_{\mathrm{O}_{2}}$ was determined using methods modified from Warburton et al. (1995). Eggs were individually sealed for 16-30 $\min$ (1-2\% fall in oxygen concentration) within an air-tight, $250 \mathrm{ml}$ mason jar/respirometry chamber that had been flushed with fresh air at $30^{\circ} \mathrm{C}$ just prior to introduction and sealing of the egg within it. Hubs from 20-gauge needles were attached into the lids and connected to a 3 -way stopcock to provide access to jar air. 60-ml syringes were used to sample air within the chamber at the end of the trial. In order to analyze gas samples from the 
respirometer jars at constant pressure and flow, samples were injected into the oxygen analyzer (S-3AI; located in the $30^{\circ} \mathrm{C}$ constant temperature room) using a reservoir/ sipper system: a T-piece connected to the oxygen analyzer and a long length of PE-50 tubing open to the room's air, the 'reservoir/sipper'. Gas samples traversed a $10 \mathrm{cc}$ column packed with Drierite to absorb water vapor and $\mathrm{CO}_{2}$ (anhydrous calcium sulfate; W. A. Hammond Drierite Co., Xenia, OH, USA). See Fig. 1 in Warburton et al. 1995 for a schematic of system. $\dot{V}_{\mathrm{O}_{2}}$ was calculated using the following equation:

$\dot{V}_{\mathrm{O}_{2}}=\frac{V_{\mathrm{c}}\left(F_{\mathrm{I}_{\mathrm{O}_{2}}}-F_{\mathrm{E}_{\mathrm{O}_{2}}}\right)}{t *\left(1-F_{\mathrm{E}_{\mathrm{O}_{2}}}\right)}$

where $\dot{V}_{\mathrm{O}_{2}}$ is oxygen consumption rate $\left(\mathrm{ml} \mathrm{O}_{2} \mathrm{~h}^{-1}\right), V_{\mathrm{c}}$ is the volume of the chamber (minus the egg volume), $F_{\mathrm{I}}$ is fraction of inspired gas, $F_{\mathrm{E}}$ is fraction of expired gas and $t$ is the measurement period $(\mathrm{h})$. Changes in gases were monitored using a PowerLab ${ }^{\circledR}$ data recording system connected to a Macintosh computer running Chart $^{\circledR}$ software, and data collected at $50 \mathrm{~Hz}$. Stable baselines, 5-7 s durations, of $F_{\mathrm{E}}$ were reliably obtained. Egg volume was determined for each egg by volume displacement. Two-four successive closed-system respirometry trials were performed on each day for each embryo $(N=8,4$ sham, 4 LAo-occluded; Day 1-surgery, Day 2-one day/ $\sim 24$-h post-operative, Day 3-two days/ $\sim 48$-h post-

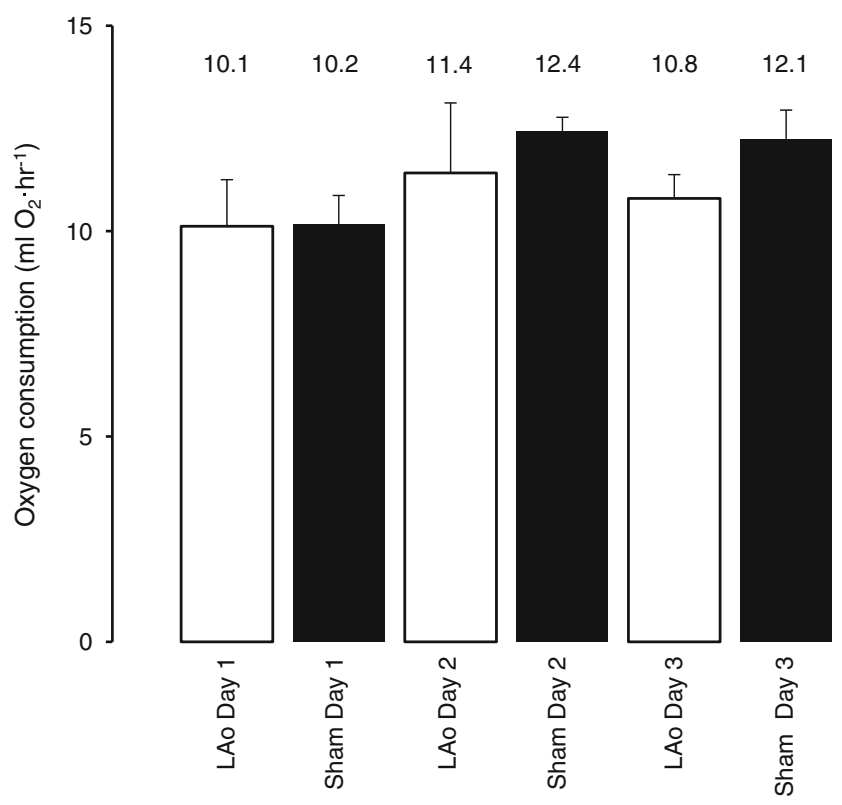

Fig. 1 Oxygen consumption $\left(\mathrm{ml} \mathrm{O}_{2} \mathrm{~h}^{-1}\right)$ of LAo-occluded (LAo, $N=4$ ) and Sham-operated (Sham, $N=4$ ) alligator embryos at $95 \%$ of development, all stage 28 embryos (Ferguson 1985). No significant difference in oxygen consumption was detected between groups $(P=0.45)$, or within groups between days of measurement $(P=0.074)$. Grand mean oxygen consumption $\left(\mathrm{ml} \mathrm{O}_{2} \mathrm{~h}^{-1}\right)$ values are given above the bars. Error bars are SEM operative). Following the final $\dot{V}_{\mathrm{O}_{2}}$ trial, the embryo was euthanized with an overdose of sodium pentobarbital (100 $\left.\mathrm{mg} \mathrm{kg}^{-1}\right)$.

Statistical analyses

Wet heart mass $(\mathrm{g})$ was adjusted for embryo mass $(\mathrm{kg})$ by dividing heart mass by embryo mass; mass-adjusted heart mass and embryo wet mass were compared between hypoxic- and normoxic-incubated embryos within the acute cardiac output and chronic CAM blood flow experiment, separately, using two-tailed Student's $t$ tests. All blood flows were adjusted for embryo mass by dividing unadjusted flow $\left(\mathrm{ml} \mathrm{min}^{-1}\right)$ by embryo mass $(\mathrm{kg})$. Chronic mean blood flow in the primary CAM artery represents the grand mean of average flow for each 1-min period during which pulsatile flow was recorded. Flows were recorded daily for each animal (1-11 days) for between 1 and $24 \mathrm{~h}$. Because total measurement time collected (1-124 h) was not equal for each animal, a two-tailed $t$ test was used to compare both mean blood flows for the first hour of each animal's trace, which was equal for all animals, and for all measurements collected for each animal, which varied from 1 to $124 \mathrm{~h}$, depending on the animal. A paired $t$ test compared the first hour and all combined measures within each oxic treatment.

For the acute cardiac output experiment, flows represent the grand mean of average flow for each 30-s period during which pulsatile flow was recorded, between 5 and 7 min of stable flow under acute normoxia or hypoxia. Combined $\dot{Q}_{\mathrm{RAo}}, \dot{Q}_{\mathrm{SCA}}$ and $\dot{Q}_{\mathrm{CCA}}\left(\dot{Q}_{\mathrm{LV}}\right.$; i.e., left ventricular cardiac output) was compared to $\dot{Q}_{\text {LAo }}$ within oxic treatments using paired $t$ tests, and a two-tailed $t$ test was used for comparisons between groups. A paired $t$ test was used to compare $\dot{Q}_{\mathrm{LV}}$ and $\dot{Q}_{\mathrm{LAo}}$ independently and collectively as the sum of $\dot{Q}_{\mathrm{LV}}$ and $\dot{Q}_{\mathrm{LAo}}$, both before and after hypoxic exposure for normoxic-incubated embryos or only during normoxic exposure for hypoxic-incubated embryos.

For the LAo occlusion $\dot{V}_{\mathrm{O}_{2}}$ experiment, a repeatedmeasures Analysis of Variance (RM-ANOVA) on $\log _{10^{-}}$ transformed $\dot{V}_{\mathrm{O}_{2}}$ 's was used to asses differences between groups (sham vs. LAo-occluded) and between days of measurement (Day 1-surgery, Day 2-one day postoperative, Day 3-two days post-operative). Multiple measurements on any single day (two-four measurements each day, per egg) were averaged to create a single data point for each day for each egg. Data were $\log _{10}$-transformed to correct for a violation of normality on a single day (Day 2) for the LAo-occluded group.

Throughout the text, means are given \pm SEM. All statistical significance was determined based on $\alpha=0.05$. 


\section{Results}

Occlusion of the left aorta (LAo) and $\dot{V}_{\mathrm{O}_{2}}$ in alligator embryos

Oxygen consumption at 95\% of development, 67-69 days post-laying, did not significantly differ between shamoperated and LAo-occluded egg within each day of measurement (RM-ANOVA on $\log _{10}$-transformed data, $F=0.95, \quad P=0.45$ ) or within one of those groups between days of measurement (RM-ANOVA on $\log _{10^{-}}$ transformed data, $F=4.6, P=0.074$; Fig. 1). Oxygen consumption trended towards increasing following recovery from anesthesia $(P=0.074$; values for Days 2 and 3 are greater than Day 1).

\section{Morphological effects of chronic hypoxia $\left(10 \% \mathrm{O}_{2}\right)$}

Hypoxic-incubated embryos at $80 \%$ of development, 56-59 days post-laying, were not significantly smaller than normoxic-incubated embryos at $80 \%$ of development (Table 1; two-tailed $t$ test, $P=0.09$ ). At $80 \%$ of development, mass-adjusted heart mass was significantly higher for hypoxic-incubated embryos when compared with normoxic-incubated embryos (two-tailed $t$ test, $P=0.03$ ). Hypoxic-incubated embryos at $90 \%$ of development, 63-66 days post-laying, were significantly smaller than normoxic-incubated embryos at $90 \%$ of development (twotailed $t$ test, $P<0.01$ ). Relative heart mass ( $\mathrm{g}$ heart $\mathrm{kg}^{-1}$ ) was significantly higher for hypoxic-incubated embryos when compared with normoxic-incubated embryos (Table $1 ; P<0.001$ ).

Qualitative comparison within normoxic and hypoxicincubated groups between 80 and $90 \%$ of development

Normoxic and hypoxic-incubated embryos at $80 \%$ of development were 58 and $38 \%$ smaller than the normoxic and hypoxic-incubated embryos at $90 \%$ of development, respectively. Relative heart mass was $52 \%$ greater for normoxic-incubated embryos at $80 \%$ of development.
Relative heart mass was $30 \%$ greater for hypoxic-incubated embryos at $80 \%$ of development (Table 1).

Physiological effects of chronic hypoxia $\left(10 \% \mathrm{O}_{2}\right)$

\section{Primary CAM artery blood flow}

Flow in the primary CAM artery in $80 \%$ of development embryos was recorded from the time of instrumentation until the loss of signal, between $1 \mathrm{~h}$ and 11 days. When all measurements were included in statistical analyses, hypoxic-incubated embryos $\left(92 \pm 26 \mathrm{ml} \mathrm{min}^{-1} \mathrm{~kg}^{-1}\right.$ for $28 \pm 19 \mathrm{~h}$ ) showed significantly elevated primary CAM artery flow when compared with normoxic-incubated embryos $\left(29 \pm 14 \mathrm{ml} \mathrm{min}^{-1} \mathrm{~kg}^{-1}\right.$ for $24 \pm 14 \mathrm{~h}$; twotailed $t$ test, $P=0.039$ ). Similarly, when only data from the first hour of recordings were compared, hypoxicincubated embryos $\left(100 \pm 35 \mathrm{ml} \mathrm{min}^{-1} \mathrm{~kg}^{-1}\right)$ showed significantly elevated blood flow as compared to normoxic-

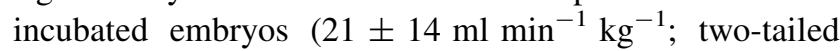
$t$ test, $P=0.036$ ). In addition, there was no significant difference between measures for the first hour and all combined measures (1-124 h) of hypoxic (paired $t$ test, $P=0.51)$ or normoxic-incubated primary CAM artery blood flow (paired $t$ test, $P=0.64$ ). $f H$ was not significantly different between normoxic (78.8 \pm 6.0 beats $\left.\min ^{-1}\right)$ and hypoxic-incubated embryos $(73.9 \pm 2.0$ beats $\min ^{-1}$; two-tailed $t$ test, $P=0.63$; all measures taken: 1-124 h). Flow profiles for the primary CAM artery were pulsatile and constant over the course of measurement.

\section{Acute cardiac output}

For anesthetized, hypoxic-incubated alligator embryos measured during hypoxia, acute $\dot{Q}_{\text {LAo }}(49.6 \pm 24.4 \mathrm{ml}$ $\min ^{-1} \mathrm{~kg}^{-1}$ ) was equivalent to the combined flow of right aorta, common carotid and subclavian arteries $\left(\dot{Q}_{\mathrm{LV}}\right.$; $43.6 \pm 21.5 \mathrm{ml} \mathrm{min}^{-1} \mathrm{~kg}^{-1}$; paired $t$ test, $P=0.86$ ). Similarly, for normoxic-incubated embryos, $\dot{Q}_{\mathrm{LAo}}$ measured under normoxic conditions $\left(27.3 \pm 6.6 \mathrm{ml} \mathrm{min}^{-1} \mathrm{~kg}^{-1}\right)$ did not differ from the combined flow of the other three

Table 1 Body mass $(\mathrm{g})$, heart mass $(\mathrm{mg})$, and relative heart masses $\left(\mathrm{g} \mathrm{kg}^{-1}\right)$ for normoxic- and hypoxic-incubated $\left(10 \% \mathrm{O}_{2}\right)$ alligator embryos

\begin{tabular}{lllccc}
\hline $\begin{array}{l}\text { Incubation } \\
\text { treatment }(N)\end{array}$ & $\begin{array}{l}\text { Developmental } \\
\text { timepoint }(\%)\end{array}$ & $\begin{array}{l}\text { Days } \\
\text { post-laying }\end{array}$ & $\begin{array}{l}\text { Body } \\
\text { mass (g) }\end{array}$ & Heart mass (mg) & $\begin{array}{l}\text { Heart mass (g) kg } \\
\text { embryo } \\
\text { Mean (SEM) }\end{array}$ \\
\hline Normoxic (6) & 80 & $56-58$ & $13.6(2.1)$ & $57.9(7.9)$ & $4.41(0.49)$ \\
Hypoxic (6) & 80 & $56-58$ & $9.8(0.4)$ & $62.0(6.6)$ & $6.38(0.76)^{\mathrm{a}}$ \\
Normoxic (5) & 90 & $63-66$ & $31.9(1.6)$ & $91.8(1.2)$ & $2.89(0.11)$ \\
Hypoxic (5) & 90 & $63-66$ & $15.9(1.5)^{\mathrm{a}}$ & $77.3(6.8)$ & $4.91(0.38)^{\mathrm{a}}$ \\
\hline
\end{tabular}

${ }^{a}$ For $t$ test results within each developmental timepoint, see Morphological effects of chronic hypoxia $\left(10 \% \mathrm{O}_{2}\right)$ in "Results" 


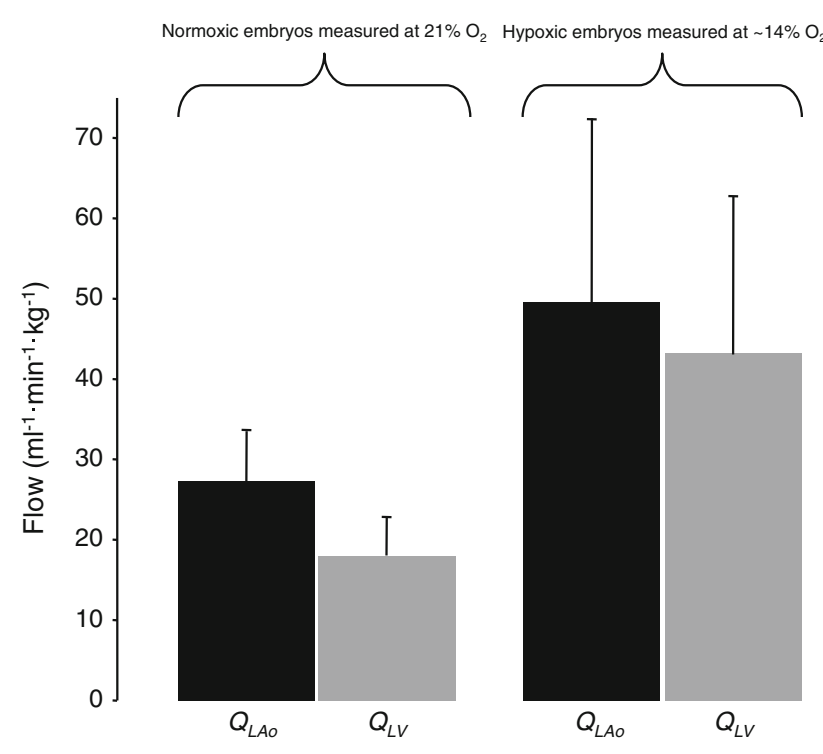

Fig. 2 Blood flow in the left aorta $\left(\dot{Q}_{\mathrm{LAo}}\right)$ and combined blood flow $\left(\dot{Q}_{\mathrm{LV}}\right)$ of the right aorta (RAo), subclavian (SCA) and common carotid arteries (CCA) for anesthetized, normoxic and hypoxicincubated embryos at $90 \%$ of development. For hypoxic-incubated embryos, $\dot{Q}_{\mathrm{LAo}}$ was equal to $\dot{Q}_{\mathrm{LV}}(N=5$; paired $t$ test, $P=0.86)$. Similarly, for normoxic-incubated embryos, $\dot{Q}_{\mathrm{LAo}}$ did not differ from $\dot{Q}_{\mathrm{LV}}(N=5$; paired $t$ test, $P=0.16)$. Error bars are SEM

vessels $\left(18.4 \pm 4.9 \mathrm{ml} \mathrm{min}^{-1} \mathrm{~kg}^{-1}\right.$; paired $t$ test, $P=0.16$; Fig. 2). $\dot{Q}_{\mathrm{LAo}}$ did not differ significantly from $\dot{Q}_{\mathrm{LV}}$ within either acute oxic treatment for a given chronic oxic incubation group, or within a chronic oxic incubation group between acute oxic treatments (Table 2). Combined blood flow of all systemic vessels (i.e., $\dot{Q}_{\mathrm{LAo}}+\dot{Q}_{\mathrm{LV}}$ ) measured during normoxia trended towards being elevated for hypoxic-incubated embryos $\left(83.3 \pm 24.3 \mathrm{ml} \mathrm{min}^{-1} \mathrm{~kg}^{-1}\right)$ as compared to normoxic-incubated embryos (45.7 \pm $10.1 \mathrm{ml} \mathrm{min}^{-1} \mathrm{~kg}^{-1}$; two-tailed $t$ test, $P=0.13$ ). Similarly, flow of all systemic vessels measured during hypoxia was higher for hypoxic-incubated embryos $(93.2 \pm 30.3$ $\mathrm{ml} \mathrm{min}{ }^{-1} \mathrm{~kg}^{-1}$ ) as compared to normoxic-incubated embryos $\left(51.7 \pm 9.31 \mathrm{ml} \mathrm{min}^{-1} \mathrm{~kg}^{-1}\right)$, but not significantly higher (two-tailed $t$ test, $P=0.17$ ). Acute hypoxic exposure caused a decrease in $f H$ for both hypoxic and normoxic-incubated embryos (paired $t$ test, $P<0.04$ ), but did not alter acute measures of $\dot{Q}_{\mathrm{LAo}}, \dot{Q}_{\mathrm{LV}}$ or $\dot{Q}_{\mathrm{LAo}}+\dot{Q}_{\mathrm{LV}}$ for hypoxic or normoxic-incubated embryos (paired $t$ tests, $P>0.15$; Table 2). Blood flows measured using a single flow probe surrounding multiple vessels exiting the LV were pulsatile, and any error due to underestimation of flows near vessel margins was likely negligible (Comeau and Hicks 1994; Fig. 3).

Qualitative comparison within normoxic-and hypoxicincubated groups between 80 and 90\% of development

Combined flow of all systemic vessels measured acutely during normoxia for normoxic-incubated embryos at $90 \%$ of development $\left(45.7 \pm 10.1 \mathrm{ml} \mathrm{min}^{-1} \mathrm{~kg}^{-1}\right)$ was elevated as compared to chronic primary CAM artery blood flow for normoxic-incubated embryos at $80 \%$ of development (e.g., $29 \pm 14 \mathrm{ml} \mathrm{min}^{-1} \mathrm{~kg}^{-1}$ for $24 \pm 14 \mathrm{~h}$ ). However, combined flow of all systemic vessels measured acutely during hypoxia for hypoxic-incubated embryos at $90 \%$ of development $\left(93.2 \pm 30.3 \mathrm{ml} \mathrm{min}^{-1} \mathrm{~kg}^{-1}\right)$ was very similar to chronic primary CAM artery blood flow for hypoxic-incubated embryos at $80 \%$ of development (e.g., $92 \pm 26 \mathrm{ml} \mathrm{min}^{-1} \mathrm{~kg}^{-1}$ for $28 \pm 19 \mathrm{~h}$ ).

\section{Discussion}

Our study demonstrates that the LAo supports a significant amount of blood flow in ovo, however, surgical occlusion of the LAo did not alter oxygen consumption, a finding similar to previous studies on sub-adult alligators (Eme et al. 2009). Chronic hypoxic incubation caused alligator embryos to be relatively smaller and have enlarged hearts, as previously described (Crossley and Altimiras 2005). In addition, hypoxic-incubated embryos also displayed

Table 2 Heart rates $(f H)$ and Mass-adjusted blood flow of the LAo $\left(Q_{\mathrm{LAo}}\right)$ and RAo, SCA and CCA $\left(Q_{\mathrm{LV}}\right)$ for normoxic- and hypoxic-incubated $\left(10 \% \mathrm{O}_{2}\right)$ alligator embryos at $90 \%$ of development during acute exposure to normoxia and hypoxia

\begin{tabular}{|c|c|c|c|c|c|c|}
\hline $\begin{array}{l}\text { Incubation } \\
\text { treatment }(N)\end{array}$ & 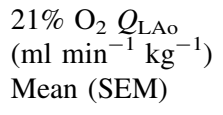 & 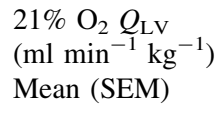 & $\begin{array}{l}21 \% \mathrm{O}_{2} \\
f H(\mathrm{BPM}) \\
\text { Mean (SEM) }\end{array}$ & $\begin{array}{l}\sim 14 \% \mathrm{O}_{2} Q_{\text {LAo }} \\
\left(\mathrm{ml} \mathrm{m^{-1 }} \mathrm{kg}^{-1}\right) \\
\text { Mean }(\mathrm{SEM})\end{array}$ & $\begin{array}{l}\sim 14 \% \mathrm{O}_{2} Q_{\mathrm{LV}} \\
\left(\mathrm{ml} \mathrm{\operatorname {min } ^ { - 1 }} \mathrm{kg}^{-1}\right) \\
\text { Mean }(\mathrm{SEM})\end{array}$ & $\begin{array}{l}\sim 14 \% \mathrm{O}_{2} \\
f H(\mathrm{BPM}) \\
\text { Mean }(\mathrm{SEM})\end{array}$ \\
\hline Normoxic (5) & $27.3(6.6)$ & $18.4(4.9)$ & $59.5(3.3)$ & $24.9(6.5)$ & $26.9(6.3)$ & $51.8(2.0)^{\ddagger}$ \\
\hline Hypoxic (5) & $38.9(11.0)$ & $44.3(23.6)$ & $56.4(5.4)$ & $49.6(24.4)$ & $43.6(21.5)$ & $47.9(4.7)^{\dagger}$ \\
\hline$P$ value within each column & 0.34 & 0.27 & 0.59 & 0.32 & 0.43 & 0.34 \\
\hline
\end{tabular}

Following acute exposure to hypoxia, heart rate was significantly lower within both the normoxic $\left({ }^{\ddagger}\right.$ paired $t$ test, $\left.P=0.034\right)$ and hypoxicincubated embryo groups $\left({ }^{\dagger}\right.$ paired $t$ test, $P=0.036$ ), compared to respective normoxic values 


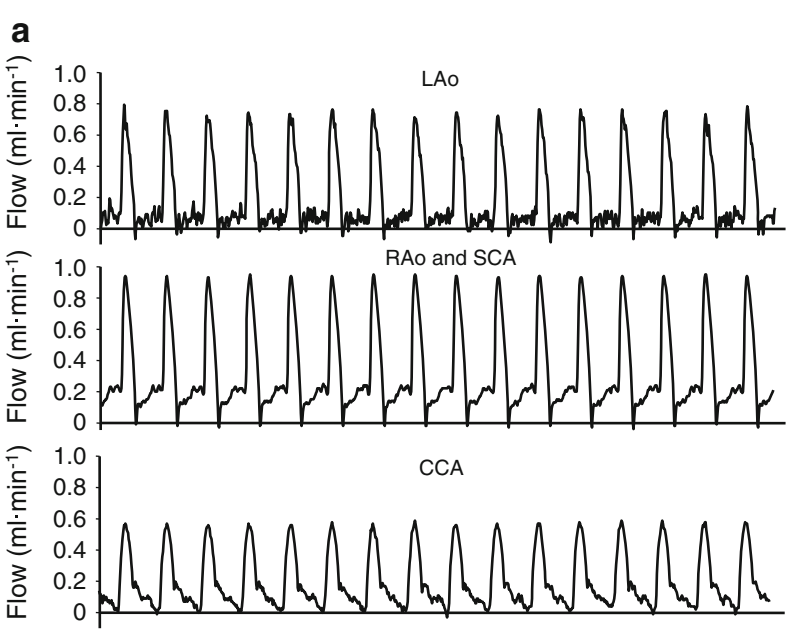

Fig. 3 Representative traces of blood flow in the systemic great vessels for alligator embryos at $\sim 90 \%$ of development, both stage 27 embryos. The hypoxic-incubated embryo (a) weighed $12.8 \mathrm{~g}$ with traces taken during exposure to hypoxia $\left(14 \pm 0.9 \% \quad \mathrm{O}_{2}\right.$; mean \pm SEM), and the normoxic-incubated embryo (b) weighed $33.6 \mathrm{~g}$ with traces taken during exposure to normoxia $\left(21 \% \mathrm{O}_{2}\right)$. Blood flow in the

increased arterial blood flow to the CAM, suggesting increased CAM vascularization or reduced vascular resistance.

The LAo supports a large amount of ventricular output in alligator embryos

In acute surgical preparations on $90 \%$ development alligator embryos, roughly half of the systemic cardiac output left the heart via the LAo, strongly indicating that the LAo allows for significant bypass of the nonfunctional lungs late in development (Fig. 2; Table 2). In embryonic birds, a $\mathrm{R}-\mathrm{L}$ cardiac shunt via ducti arteriosi is responsible for directing pulmonary blood away from the non-functional lungs. Ducti arteriosi are present in reptilian embryos as well, and are anatomically similar to that of birds (Bergwerff et al. 1999). For all reptiles, the LAo may provide a significant additional pathway for pulmonary blood to bypass the lungs. Interestingly, the relative size of the ducti arteriosi compared to the other systemic vessels is reduced in alligator embryos as compared to domestic chicken embryos (E. M. Dzialowski personal communication). We did not measure blood flow in the ducti arteriosi or pulmonary artery due to technical constraints, but blood filling the pulmonary artery during acute cardiac output experiments was observed. However, the large forward blood flow recorded in the LAo of embryonic alligators was similar in magnitude to the cardiac output of the left ventricle, and it is unlikely that this large blood flow originated from the left ventricle and traversed the FoP, but rather,

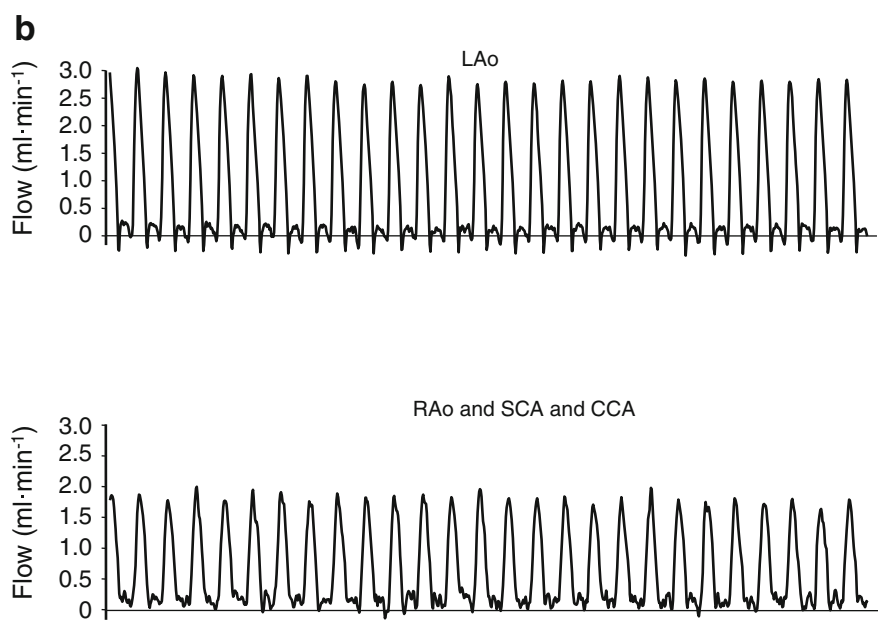

left aorta $\left(\dot{Q}_{\mathrm{LAo}}\right)$ was measured using a single flow probe. Blood flows taken simultaneously in a single flow probe for vessels exiting the left ventricle (LV) were pulsatile, either right aorta (RAo) and subclavian artery (SCA) or RAo, SCA and common carotid artery (CCA)

that the majority of crocodilian embryonic LAo flow originates from the right ventricle late in development.

Occlusion of the LAo in ovo does not affect oxygen consumption

Despite the significant amount of blood flow supported by the LAo, its downstream occlusion did not affect egg oxygen consumption. Our values for oxygen consumption $\left(10-12 \mathrm{ml} \mathrm{O}_{2} \mathrm{~h}^{-1}\right)$ of alligator eggs at $95 \%$ of development are slightly higher to those obtained for crocodilians at similar stages of incubation. Warburton et al. (1995) reported $\dot{V}_{\mathrm{O}_{2}}$ 's of $8-9 \mathrm{ml} \mathrm{O}_{2} \mathrm{~h}^{-1}$ for alligator embryos at 70-77 days of incubation ( $\geq 95 \%$ of development), and Booth (2000) reported $\dot{V}_{\mathrm{O}_{2}}$ 's of $\sim 10 \mathrm{ml} \mathrm{O}_{2} \mathrm{~h}^{-1}$ for estuarine crocodile embryos (Crocodylus porosus) at $\sim 85 \%$ of development. A recent study demonstrated that complete surgical occlusion of the LAo, both upstream and downstream of the FoP, did not affect resting oxygen consumption or ventilation in juvenile alligators, despite chronic ventricular enlargement presumably resulting from increased right ventricular afterload (Eme et al. 2009). Our observations on the effects of LAo occlusion on embryo $\dot{V}_{\mathrm{O}_{2}}$ are consistent with Eme et al. (2009). While we measured significant blood flow in the LAo in all embryos in the acute cardiac output experiment, indicating an important pathway bypassing the non-functional lungs, occlusion of the LAo did not affect egg oxygen consumption. It does not seem that either potential LAo blood flow joining with the right aorta, downstream of their 
fusion into the abdominal aorta, or oxygenation of the developing embryo and its yolk via the LAo-celiac artery route are important to maintain egg oxygen consumption. However, blood flow at the fusion of the LAo with the right aorta and the presence of ducti arteriosi, as well as possible FoP flow, may maintain CAM flow and oxygen consumption following downstream LAo occlusion.

Comparison of blood flow in the CAM of American alligator and chicken embryos in normoxia and hypoxia

This study contains the first direct measurement of blood flow in the primary CAM artery for a reptile embryo and demonstrates that chronic hypoxic incubation of $>40$ days increased CAM flow in alligator embryos. Hypoxia is a natural environmental challenge for embryonic reptiles, with eggs laid underground or in mound nests possibly exposed to both acute and chronic hypoxia (Lutz and Dunbar-Cooper 1984; Seymour et al. 1986; Booth 1998, 2000). Hypoxia can result from changes in gas conductance within the nest, rising egg metabolism and/or metabolic activity of nest organisms, and previous studies have shown that hypoxic stress can alter both morphological and physiological development in reptiles. Regional hypoxia increases vascularization of the CAM in alligators (Corona and Warburton 2000), and addition of these parallel vascular beds reduces vascular resistance, which could account for the reduction in systemic pressure (Crossley and Altimiras 2005). Chronic, 'whole-egg' hypoxic incubation of embryonic turtles (Pseudemys nelsoni) causes a metabolic depression, increased hematocrit and ventricular hypertrophy likely caused by increased workload on more viscous blood (Kam 1993). Similarly, hypoxic incubation in embryonic alligators also results in an increased hematocrit (Warburton et al. 1995), enlargement of the heart (present study; Crossley and Altimiras 2005) and lower mean arterial pressure and $f H$ (Crossley and Altimiras 2005). While whole-CAM vascular resistance was not quantified during our chronic studies, prior work demonstrated that chronic hypoxia decreased vascular resistance in embryonic chickens (Adair et al. 1987). In addition, hypoxia increases the heart weight:body weight ratio of chicken embryos (Rouwet et al. 2002).

The relative cardiac enlargement resulting from chronic hypoxia could be due to direct actions on the cardiomyocytes, or due to indirect reactions in response to mechanical changes (venous return and/or afterload) or hormonal changes (adrenergic-induced increase in contractile force). Elevated levels of plasma catecholamines have been demonstrated during both acute hypoxia in embryonic chickens (Crossley et al. 2003) and in alligators incubated under a chronic hypoxic challenge, supporting the hormonal speculation (Altimiras and Crossley unpublished observation). Further, the increase in CAM arterial flow, as demonstrated by our chronic experiments, may be required to support the increase in CAM vascular area previously documented in these animals (Corona and Warburton 2000). However, if alligator cardiac output remains the same, as suggested by the present study's nonsignificant rise in total flow, the observed elevation in CAM flow may be due to an increase in intraembryonic vascular resistance, which may also contribute to the increase in cardiac mass. Investigations of cardiac output distributed to the CAM in embryonic chickens, estimated using fluorescent microspheres, showed an increase during exposure to $100 \% \mathrm{~N}_{2}$ and the magnitude of the response increased with incubation time (Mulder et al. 1998, 2002). Conversely, direct measures of primary CAM blood flow using flow probes in domestic chicken embryos (Gallus gallus) showed that acute hypoxia decreased blood flow to the CAM (Tazawa et al. 1985; van Golde et al. 1997). Exposure to hypoxia ( 6 or $11 \% \mathrm{O}_{2}$ ) reduced flow in the primary CAM artery by only $10 \%$, but $100 \% \mathrm{~N}_{2}$ caused significant bradycardia, cardiac arrhythmia and markedly reduced allantoic blood flow (Tazawa et al. 1985), and in the other study, exposure to $5 \% \mathrm{O}_{2}$ caused a marked and reversible decrease in primary CAM blood flow (van Golde et al. 1997). Therefore, the embryonic capacity to increase CAM perfusion during periods of reduced $\mathrm{O}_{2}$ may be restricted to species that routinely experience these conditions in their natural environment, i.e., reptiles. However, an alligator eggshell has gas conductance values approximately four times higher than that of an equivalent avian egg, based on water conductance calculations (Deeming and Thompson 1991). Under control conditions, embryonic alligators would be predicted to exhibit elevated blood $P_{\mathrm{O}_{2}}$ levels compared to a similar sized bird embryo, and the hypoxic stress applied during this study likely results in greater change in $P_{\mathrm{O}_{2}}$ in American alligator embryos compared to an equivalent stress in embryonic birds, possibly necessitating increased the arterial CAM blood flow we have shown.

\section{Summary}

For a reptile embryo, this study represents the first measurement of primary CAM arterial blood flow and great vessel blood flow (systemic cardiac output), as well as the first central cardiac surgical manipulation. Hypoxia increases blood flow in the primary CAM artery of embryonic alligators, and along with increased CAM vascularization or reduced resistance, may be a primary mechanism to enhance oxygen extraction (Corona and Warburton 2000). The LAo plays a central role in the 
systemic cardiac output of embryonic alligators and may provide a utilized pathway for diverting blood away from the non-functioning lungs in all embryonic reptiles. However, despite this role, blood flow through the LAo is not necessary for maintaining the normal oxygen consumption of alligator embryos. Data reported in the present study, together with other recent reptilian studies (Wang and Hicks 2008; Eme et al. 2009, 2010), support a hypothesis reiterated by Eme et al. (2009, 2010) (e.g., Foxon 1955; Hicks 2002), namely that the low metabolism of extant ectothermic reptiles precludes a metabolic benefit of the dual aortic arch system of reptiles. These data suggest the four-chambered crocodilian heart and dual aortic arch system are plesiomorphic characters that have not been selected against.

Acknowledgments The authors sincerely thank the following individuals for their help in these studies: Ruth Elsey (RWR) for access to alligator eggs and her invaluable, continuing support of our research, Sabee Molloi for generating the digital subtraction angiography video in Supplementary Fig. 1, and Kevin Tate and Magnus Elfwing for assistance with embryo care and data collection. This work was supported by NSF Career award IBN IOS-0845741 to DAC and NSF award IOB-0445680 to JWH. JE was supported for part of this study by NSF GK-12 grant number DGE-0638751, and travel monies were provided to JE through a JEB Travelling Fellowship (The Company of Biologists, Ltd.).

Open Access This article is distributed under the terms of the Creative Commons Attribution Noncommercial License which permits any noncommercial use, distribution, and reproduction in any medium, provided the original author(s) and source are credited.

\section{References}

Adair T, Guyton AC, Montani JP, Lindsay HL, Stanek KA (1987) Whole body structural vascular adaptation to prolonged hypoxia in chick embryos. Am J Physiol (Heart Circ Physiol) 252:H1228-H1234

Bergwerff M, DeRuiter MC, Gittenberger-de Groot AC (1999) Comparative anatomy and ontogeny of the ductus arteriosus, a vascular outsider. Anat Embryol 200:559-571

Booth DT (1998) Nest temperature and respiratory gases during natural incubation in the broad-shelled river turtle, Chelodina expansa (Testudinata:Chelidae). Aus J Zool 46:183-191

Booth DT (2000) The effect of hypoxia on oxygen consumption of embryonic estuarine crocodiles (Crocodylus porosus). J Herp 34:478-481

Comeau SG, Hicks JW (1994) Regulation of central vascular blood flow in the turtle. Am J Physiol 267:R569-R578

Corona TB, Warburton SJ (2000) Regional hypoxia elicits regional changes in chorioallantoic membrane vascular density in alligator but not chicken embryos. Comp Biochem Physiol A 125:57-61

Crossley DA II, Altimiras J (2005) Cardiovascular development in embryos of the American Alligator Alligator mississippiensis: effects of chronic and acute hypoxia. J Exp Biol 208:31-39

Crossley DA II, Burggren WW, Altimiras J (2003) Cardiovascular regulation during hypoxia in embryos of the domestic chicken
Gallus gallus. Am J Physiol Regul Interg Comp Physiol 284:R219-R226

Deeming DC, Thompson MB (1991) Gas exchange across reptilian egg shells. In: Deeming DC, Ferguson MWJ (eds) Egg incubation its effects on embryonic development in birds and reptiles. Cambridge University Press, Cambridge, pp 277-284

Eme J, Gwalthney J, Blank JM, Owerkowicz T, Barron G, Hicks JW (2009) Surgical removal of right-to-left cardiac shunt in the American alligator (Alligator mississippiensis) causes ventricular enlargement but does not alter apnoea or metabolism during diving. J Exp Biol 212:3553-3563

Eme J, Gwalthney J, Owerkowicz T, Blank JM, Hicks JW (2010) Turning Crocodilian hearts into Bird hearts: Growth rates are similar for alligators with and without right-to-left cardiac shunt. $\mathrm{J}$ Exp Biol (in press)

Farmer CG, Uriona TJ, Olsen DB, Steenblick M, Sanders K (2008) The right-to-left shunt of crocodilians serves digestion. Physiol Biochem Zool 81:125-137

Ferguson MWJ (1985) Reproductive biology and embryology of the crocodilians. In: Gans C, Billet F, Maderson P (eds) Biology of the reptilia, vol 14 A. Wiley, New York, pp 329-349

Foxon GEH (1955) Problems of the double circulation in vertebrates. Biol Rev 30:196-228

Grigg GC, Johansen K (1987) Cardiovascular dynamics in Crocodylus porosus breathing air and during voluntary aerobic dives. J Comp Physiol B 157:381-392

Hicks JW (1998) Cardiac shunting in reptiles: mechanisms, regulation, and physiological function. In: Gans C, Gaunt AS (eds) Biology of the Reptilia, vol 19 G. SSAR Press, Ithaca, pp 425-483

Hicks JW (2002) The physiological and evolutionary significance of cardiovascular shunting patterns in reptiles. News Physiol Sci $17: 241-245$

Hicks JW, Wang T (1996) Functional role of cardiac shunts in reptiles. J Exp Zool 275:204-216

Jones DR, Shelton G (1993) The physiology of the alligator heartleft aortic flow patterns and right-to-left shunts. J Exp Biol 176:247-269

Kam YC (1993) Physiological effects of hypoxia on metabolism and growth of turtle embryos. Resp Physiol 92:127-138

Lutz PL, Dunbar-Cooper A (1984) The nest environment of the American Crocodile (Crocodylus acutus). Copeia 1:153-161

Mulder ALM, van Golde JC, Prinzen FW, Blanco CE (1998) Cardiac output distribution in response to hypoxia in the chick embryo in the second half of the incubation time. J Physiol 508:281-287

Mulder ALM, Miedema A, DeMay JGR, Giussani DA, Blanco CE (2002) Sympathetic control of the cardiovascular response to acute hypoxemia in the chick embryo. Am J Physiol 282:R1156R1163

Panizza B (1833) Sulla struttura del cuore e sulla circolazione del angue del Crocodilus lucius. Biblioth Ital 70:87-91

Piiper J, Hiroshi T, Ar A, Rahn H (1980) Analysis of chorioallantoic gas exchange in the chick embryo. Resp Physiol 39:273-284

Rouwet EV, Tintu AN, Shellings MWM, van Bilsen M, Lutgens E, Hofstra L, Slaaf DW, Ramsay G, le Noble FAC (2002) Hypoxia induces aortic hypertrophic growth, left ventricular dysfunction and sympathetic hyperinnervation of peripheral arteries in the chick embryo. Circulation 105:2791-2796

Seymour RS, Wagner-Amos K (2008) Non-invasive measurement of oxygen partial pressure, lateral diffusion and chorioallantoic blood flow under the avian eggshell. Comp Biochem Physiol A 150:258-264

Seymour RS, Vleck D, Vleck CM (1986) Gas exchange in the incubation mounds of megapode birds. J Comp Physiol B 156:772-782

Seymour RS, Bennett-Stamper CL, Johnston SD, Carrier DR, Grigg GC (2004) Evidence for endothermic ancestors of Crocodiles at 
the stem of Archosaur evolution. Physiol Biochem Zool 77:1051-1067

Tazawa H, Mochizuki M (1977) Oxygen analyses of chicken embryo blood. Resp Physiol 31:203-215

Tazawa H, Lomholt JP, Johansen K (1985) Direct measurement of allantoic blood flow in the chicken, Gallus domesticus. Responses to alteration in ambient temperature and $\mathrm{PO}_{2}$. Comp Biochem Physiol A 81:641-642

van Golde J, Mulder T, Blanco CE (1997) Changes in mean chorioallantoic artery blood flow and heart rate produced by hypoxia in the developing chick embryo. Pediatr Res 42:293-298
Wang T, Hicks JW (2008) Changes in pulmonary blood flow do not affect gas exchange during intermittent ventilation in resting turtles. J Exp Biol 211:3759-3763

Warburton SJ, Hastings D, Wang T (1995) Responses to chronic hypoxia in embryonic Alligators. J Exp Ziol 273:44-50

Webb GJW (1979) Comparative cardiac anatomy of the reptilian III. The heart of crocodilians and a hypothesis on the completion of the interventricular septum of crocodilians and birds. J Morph $161: 221-240$ 